\section{Hyperuricemia and Early-onset Chronic Kidney Disease in a 7-year-old Child}

Familial juvenile hyperuricemic nephropathy (FJHN) is a rare and difficult to manage disease. Early diagnosis, early treatment with allopurinol and regular follow up can ameliorate the long-term progression to end-stage renal disease. We report a 7-year-old, asymptomatic patient with anemia, reduced renal function and hyperuricemia. Genetic screening played a crucial role in establishing the diagnosis.

A 7-year-old girl was referred to our clinic due to abnormal renal function tests noted in laboratory work-up for assessment of chronic anemia. Her past medical history was otherwise unremarkable. She was the fourth child of her family and there was no family history of renal pathology, except for diabetic nephropathy in the grandfather. Upon admission, her blood pressure was $123 / 93 \mathrm{mmHg}\left(99^{\text {th }}\right.$ centile $)$, weight $24 \mathrm{~kg}$ $\left(25^{\text {th }}\right.$ centile $)$ and height $127.5 \mathrm{~cm}\left(75^{\text {th }}\right.$ centile $)$. Systemic examination was normal. Laboratory examination revealed increased blood urea nitrogen (BUN) $(61 \mathrm{mg} / \mathrm{dL})$, serum creatinine $(1.23 \mathrm{mg} / \mathrm{dL})$ and serum uric acid $(8.52 \mathrm{mg} / \mathrm{dL})$. The hematocrit was $32.3 \%$, hemoglobin $10.8 \mathrm{~g} / \mathrm{dL}$, MCV $79.7 \mathrm{fL}$, $\mathrm{MCH} 26.7 \mathrm{pg}$ and MCHC 33.5. Rest of the laboratory results were within normal limits. The glomerular filtration rate (GFR) was calculated as $65.5 \mathrm{~mL} / \mathrm{min} / 1.73 \mathrm{~m}^{2}$ (stage 2 chronic renal disease). Fractional excretion of uric acid was $6 \%$ (normal range $18 \pm 5 \%$ ). Urine analysis results showed no abnormality. On sonographic examination, right kidney length was $7 \mathrm{~cm}$ and left kidney length $6.9 \mathrm{~cm}\left(25^{\text {th }}\right.$ centile $)$, with increased cortical echogenicity of both kidneys, suggestive of parenchymal renal disease. Further imaging with mercaptoacetyltriglycine (MAG3) diuretic renogram indicated a moderate loss in renal function of both kidneys.

The laboratory and imaging findings were consistent with renal cortical necrosis. However, there was no previous medical history indicating a causative factor such as, chronic lead nephropathy or exposure to toxins and drugs for above findings. Moreover, the increased level of blood uric acid combined with its reduced fractional renal excretion could not be attributed only to the degree of renal failure. Thus, the possible diagnosis seemed to be genetic, most likely FJHN. In order to confirm the diagnosis, genetic testing was carried out. Mutation analysis of Uromodulin, the gene known to encode Tamm-Horsfall protein, revealed an in-frame deletion between nucleotides 668-767 and a replacement of conservative Glu 188 by an irrelevant valine, leading to a defective protein with 2 of 24 consecutive cysteine residues being removed. Cysteine residues are thought to be crucial in the cross-linking of the protein. Mutations involving them alter its tertiary structure and are commonly found in autosomal dominant tubulointerstitial kidney diseases (ADTKD) such as FJHN
[1]. Our patient progressed to end stage renal failure at the age of 12 years. Her anemia, which was normocytic, normochromic was attributed to the chronic renal disease and was treated with erythropoetin. With the exception of renin (REN) gene-related ADTKD and nephronophthisis, anemia is not considered a typical finding of the condition [2]. The patient received a cadaver kidney transplant after 1 year of peritoneal dialysis, since the disease does not recur in the graft.

Familial juvenile hyperuricemic nephropathy is a rare genetic disease which falls into the category of ADTKD [2]. It is characterized by reduced renal excretion of urate, early onset hyperuricemia and slow progression to chronic end-stage renal disease. The exact pathophysiologic mechanism of the disease is not yet fully understood. It is presumed that mutations in the gene encoding Tamm-Horsfall protein, the most abundant protein in the urine, induce tubular dysfunction and subsequent uric acid retention $[3,4]$. FJHN is an autosomaldominant disorder but this particular case did not have the expected findings of chronic renal disease, early hyperuricemia and episodes of gout [2]. Even in this case, ADTKD should still be considered in the differential diagnosis, as these may be de novo cases or with wrong diagnoses in other relatives $[5,6]$. Attempts can be made to select patients at risk of chronic kidney disease as a part of appropriate genetic counseling, which aims to detect them and improve their prognosis.

Despoina Tramma* and Despoina Samourkasidou Department of Pediatrics-Pediatric Nephrology, $4^{\text {th }}$ Pediatric Department, Aristotle University of Thessaloniki, Papageorgiou General Hospital, Thessaloniki, Greece.

\section{REFERENCES} *dtramma@auth.gr

1. Schäffer P, Gombos E, Meichelbeck K, Kiss A, Hart PS, Bleyer AJ. Childhood course of renal insufficiency in a family with uromodulin gene mutation. Pediatr Nephrol. 2010;25:1355-60.

2. Eckardt K-U, Alper SL, Antignac C, Bleyer AJ, Chauveau $\mathrm{D}$, Dahan $\mathrm{K}$, et al. Autosomal dominant tubulointerstitial kidney disease: diagnosis, classification, and management A KDIGO consensus report. Kidney Int.2015;88:676-83.

3. Liu M, Chen Y, Liang Y, Liu Y, Wang S, Hou P, Zhang, et al. Novel UMOD mutations in familial juvenile hyperuricemic nephropathy lead to abnormal uromodulin intracellular trafficking. Gene. 2013;531:363-9.

4. Hart TC, Gorry MC, Hart PS, Woodard AS, Shihabi Z, Sandhu J, et al. Mutations of the UMOD gene are responsible for medullary cystic kidney disease 2 and familial juvenile hyperuricaemic nephropathy. J Med Genet. 2002;39:882-92.

5. Malakoutian T, Amouzegar A, Vali F, Asgari M, Behnam B. First Report of familial juvenile hyperuricemic nephropathy (FJHN) in Iran caused by a novel de novo mutation (E197X) in UMOD. J Mol Genet Med. 2016;10:218.

6. Wheeler E, Thomas S. Diagnosis and long-term management of uromodulin kidney disease. Cureus.2019;11:e4270. 